\title{
Effects of High Intensity Exercise on Body Composition Measured by Bioelectrical Impedance Analysis
}

\section{Yüksek Şiddetli Egzersizin Bioelektrik İmpedans Yöntemi İle Ölçülen Vücut Kompozisyonu Üzerine Etkisi}

\author{
Tahir Hazır ${ }^{1}$, Mehmet Gören Köse ${ }^{1}$, Ferhat Esatbeyoğlu², Yunus Emre Ekinci' ${ }^{1}$, Ayşe Kin İşler ${ }^{1}$ \\ ${ }^{1}$ Department of Exercise and Sport Sciences, Faculty of Sport Sciences, Hacettepe University, Ankara, Turkey \\ ${ }^{2}$ Department of Sports Sciences and Technology, Institute of Health Sciences, Hacettepe University, Ankara, Turkey
}

T. Hazır

0000-0002-0048-0281

M. G. Köse

0000-0002-1694-655x

F. Esatbeyoğlu iD

0000-0002-4184-5582

Y. E. Ekinci in

0000-0002-1799-2742

A. Kin İșler

0000-0001-9651-2067

Geliş Tarihi/Date Received:

28.06.2019

Kabul Tarihi/Date Accepted: 28.08.2019

Yayın Tarihi/Published Online: 23.01.2020

Yazışma Adresi /

Corresponding Author:

Ayse Kin İşler

Hacettepe Üniversitesi,

Egzersiz ve Spor Bilimleri

Bölümü, Hareket ve

Antrenman Bilimleri Anabilim

Dalı, Ankara, Turkey

E-mail: aysekin@gmail.com

(C2020 Türkiye Spor Hekimleri Derneği. Tüm hakları saklıdır.

\section{ABSTRACT}

Objective: It is recommended not to exercise for $12-48$ hours prior to test to secure validity and reliability of bioelectrical impedance analysis (BIA) method. The aim of this study was to examine the effect of repeated cycling sprint exercise on body composition using foot-to-foot and hand-to-foot $\mathrm{BIA}\left(\mathrm{BI} \mathrm{A}_{\mathrm{F}-\mathrm{F}}\right.$ and $\left.\mathrm{BI} \mathrm{A}_{\mathrm{H}-\mathrm{F}}\right)$.

Material and Method: Twenty five young recreationally active men $(23.7 \pm 6.3$ years) completed a repeated cycling sprint test (5x6-s max sprints with $30 \mathrm{~s}$ rest). Body mass (BM), fat-free mass (FFM), body fat percentage (BFP), BIA $A_{F-F}$ and $B I A_{H-F}$, impedance, resistance and reactant values were measured prior to repeated cycling sprint test, immediately after (1-3 minutes) and following 10th and 20th minutes of the test. The effects of exercise on body composition and BIA values were determined by repeated measures variance analysis.

Results: When compared to values prior to exercise, significant decrease in BM was found beginning from the 10th minute following the exercise $(p<0.001)$. For $B I A_{F-F}$ method, comparing prior to exercise; impedance and BFP measured following exercise were significantly lower till 20th minute following the exercise $(p<0.001)$ whereas FFM was significantly higher $(p<0.009)$. These differences revealed a change less than $2.0 \%$ for BFP and less than $0.40 \%$ for FFM. For BIA $\mathrm{H}_{-\mathrm{F}}$ method, comparing with prior to highintensity exercise, resistance values immediately after and 10 minutes after exercise were similar, however, resistance values after 20 minutes were measured significantly lower $(p<0.001)$. On the other hand, there is no significant change found in reactant values $(p>0.05)$. The effects of high-intensity exercise on BFP $(p>0.05)$ and FFM $(p>0.05)$ measured with $\mathrm{BIA}_{\mathrm{H}-\mathrm{F}}$ method was not significant.

Conclusion:The results of this study showed that short-term high-intensity exercise had no effect on body composition measured by $\mathrm{BIA}_{\mathrm{H}-\mathrm{F}}$ technology. In addition, BFP measured by $\mathrm{BIA}_{\mathrm{F}-\mathrm{F}}$ technology was significantly low, but this decrease was less than $2 \%$. These results indicate that exercise restriction before BIA measurement is not evidence based, if the hydration status is well-controlled.

Keywords: High-Intensity Exercise, Bioelectrical Impedance Analysis, Body Composition

\section{öz}

Amaç: Bioelektrik impedans analizi (BIA) yönteminin geçerliği ve güvenirliği için testten önceki 12-48 saat egzersiz yapılmaması tavsiye edilmektedir. Bu çalışmanın amacı bisiklet ergometresinde tekrarlı sprint egzersizinin ayaktan ayağa $\left(B I A_{A-A}\right)$ ve elden ayağa $\left(B I A_{E-A}\right)$ BIA yöntemi ile belirlenen vücut kompozisyonu üzerine etkisini incelemektir. 
Gereç ve Yöntem: Yirmibeş genç aktif erkeğe (23.7 \pm 6.3 yaş) bisiklet ergometresinde $5 \times 6$ saniye tekrarlı sprint egzersizi yaptırımıştır. Test öncesinde, testten hemen sonra (1-3 dakika) ve test bitiminin 10. ve 20. dakikalarında katılımcıların vücut ağırlığı (VA), sırasıyla $B_{A} A_{A-A}$ ve $B I A_{E-A}$ yöntemleri ile vücut yağ yüzdesi (VYY), ve yağsız vücut kitlesi (YVK), impedans, rezistans ve reaktans değerleri ölçülmüştür. Egzersizin vücut kompozisyonu ve BIA çıktıları üzerine etkisi tekrarlı ölçümlerde varyans analizi ile belirlenmiştir.

Bulgular: Egzersiz öncesiyle karşılaştırıldığında 10. dakikadan itibaren VA'da anlamlı düşüş saptanmıştır $(p<0.001)$. $\mathrm{BIA}_{\mathrm{A}-\mathrm{A}}$ yönteminde egzersiz öncesi ile karşılaştırıldığında egzersizden sonra ölçülen impedans ve VYY 20. dakikaya kadar anlamlı derecede düşük $(p<0.001)$, buna karşılık $Y V K$ anlamlı derecede yüksek $(p<0.01)$ ölçülmüştür. Bu farklar VYY için \%2.0'den, YVK için ise \%0.40'dan az değişimi temsil etmektedir. BIA egzersiz öncesi ile karşılaştırıldığında egzersizden hemen sonra ve 10. dakikada ölçülen rezistans değerleri benzer ancak 20. dakikada anlamlı derecede düşük ölçülmüştür $(p<0.001)$. Buna karşılık reaktans değerlerinde anlamlı bir değişim saptanmamıştır ( $p>0.05)$. Yüksek şiddette egzersizin BIA $A_{E-A}$ yöntemi ile belirlenen VYY $(p>0.05)$ ve $Y V K$ ( $p>0.05)$ üzerine etkisi anlamlı değildir.

Sonuç: $\mathrm{Bu}$ çalışmanın bulguları kısa süreli yüksek şiddetli egzersizin BIA $\mathrm{E}-A_{\text {A }}$ teknolojisi ile ölçülen vücut kompozisyonu üzerine etkisi olmadığını göstermiştir. Ek olarak, BIA $A$-A teknolojisi ile ölçülen VYY anlamlı derecede düşük olmakla beraber, bu düşüş \%2'den azdır. Bu bulgular hidrasyon durumu kontrol altında tutulduğunda BIA ölçümü öncesi egzersiz kısıtlamasının kanıta dayalı olmadığını göstermektedir.

Anahtar sözcükler: Yüksek şiddetli egzersiz, Bioelektrik Impedans Analizi, Vücut Kompozisyonu

Available at: http://journalofsportsmedicine.org and http://dx.doi.org/10.5152/tjsm.2020.166

Cite this article as: Hazir T, Kose MG, Esatbeyoglu F, Ekinci YE, Kin Isler A. Effects of high intensity exercise on body composition measured by bioelectrical impedance analysis. Turk J Sports Med. 2020;55(2):102-11.

\section{GíRiş}

Vücut kompozisyonu ölçümü atletik performansı değerlendirmek, sağlık için yapılan kuvvet-dayanıklılık egzersizlerinin ve bireysel olarak kilo verme programlarının etkisini gözlemlemek için yaygın olarak kullanılmaktadır. Sualtı tartım yöntemi (STY)(1) ve DEXA (2) vücut kompozisyonunun değerlendirilmesinde referans yöntemler olmakla beraber, STY'nin çok teknik ve zaman alıcı, DEXA'nın ise çok pahalı ve ulaşılması zor bir yöntem olması nedeniyle spor ve sağlık ile ilgili programlarda pratik kullanım değerleri düşüktür. Biyoelektrik impedans (BIA) yöntemi nispeten ucuz, bilgi beceri gerektirmeyen ve kolay ulaşılan bir yöntem olup, hem atletik popülasyonda $(3,4)$ hem de sağlık için egzersiz programlarında ve özellikle kalabalık popülasyonların vücut kompozisyonunun değerlendirilmesinde $(5,6)$ yüksek kullanım değerine sahiptir. BIA, kas ve yağ doku gibi farklı biyolojik dokuların, uygulanan elektrik akımına karşı oluşturduğu direnç farklılıklarına bağlı olarak vücut kompozisyonun değerlendirilmesine olanak sağlayan bir teknolojidir (7). Genel olarak $50 \mathrm{kHz}$ değerinde tek bir frekans kullanılması ve bu frekanstaki akımın tüm vücut sıvılarına nüfuz etmemesi, BIA yönteminin en önemli sinırlılığı olarak kabul edilmektedir (8).
Egzersizin BIA ile belirlenen vücut kompozisyonu parametreleri üzerine etkisi ile ilgili çalışmalar uzun süreli, değişik şiddette aerobik ve kuvvet egzersizlerine odaklanmıştır. Aerobik egzersizlerden elde edilen bulgular, egzersiz şiddetinin BIA temelli vücut kompozisyonu değerlendirmelerini önemli ölçüde etkilediğini göstermiştir (9-12). Yüksek şiddette egzersiz sirasında su, $\left[\mathrm{Na}^{+}\right]$ve $\left[\mathrm{Cl}^{-}\right]$iyonlarının plazmadan aktif kaslara, laktik asit ve $\left[\mathrm{K}^{+}\right]$iyonlarının aktif kaslardan plazmaya geçtiği (13) ve egzersiz sonrasında ise 1 dakika içerisinde $\left[\mathrm{K}^{+}\right]$iyonları plazmadan kas içerisine kaydığı için (14) egzersiz, vücut bölümleri arasında elektrolit dengesinde önemli değișime neden olur. Egzersiz öncesi ile karşılaştırıldığında, yüksek hacim-orta şiddette kuvvet egzersizlerinde daha fazla olmak kaydıyla, düşük hacim-yüksek şiddette kuvvet egzersizlerinden hemen, 30 dakika ve 60 dakika sonra plazma osmolalitesinde ve $\left[\mathrm{Na}^{+}\right]$ iyon konsantrasyonunda anlamlı derecede artış rapor edilmiştir (15). Kuvvet egzersizleri sırasında ekstrasellüler alan (kan) ve iskelet kasları arasında önemli miktarda sıvı değișimi olmasına rağmen (16), öncesinde kuvvet egzersizi yapıldığında $\mathrm{BIA}_{\mathrm{A}-\mathrm{A}}$ 'dan belirlenen vücut kompozisyonunda önemli değişim saptanmamıştır (17). Uzun süreli aerobik egzersizlerin 
ve kuvvet antrenmanlarının BIA yöntemi üzerine etkisi araştırılmış, ancak alt ekstremite kaslarına yönelik yüksek şiddetli kısa süreli kesintili egzersizlerin BIA $_{A-A}$ ve BIA $A_{E-A}$ vücut kompozisyonu ölçümlerini nasıl etkilediği incelenmemiştir. Buradan hareketle, bu çalışmanın amacı bisiklet ergometresinde tekrarlı sprint egzersizinin BIA $_{A-A}$ ve BIA $A_{E-A}$ yöntemi ile belirlenen vücut kompozisyonu üzerine etkisini incelemektir.

\section{GEREÇ ve YÖNTEMLER}

Araștırma Grubu: Bu çalıșmanın araștırma grubu 18-30 yaş arası rekreasyonel aktif, alt ekstremite spor yaralanması öyküsü olmayan 25 erkek gönüllüden (Yaş=23.7 \pm 6.3 yıl; Boy $=175.6 \pm 4.8 \mathrm{~cm}$; BKI=25.8 $\pm 2.5 \mathrm{~kg} \cdot \mathrm{m}^{-2}$ ) oluşturulmuştur. Beden Kitle İndeksine (BKI) göre 11 katılımcl normal (BKI = 18.5-24.9), 12 katılımcı fazla kilolu (BKI $=25.0-29.9), 2$ katılımcı obezite sınıf I (BKI = 30.0-34.9) kategorisindedir (18). Fiziksel Aktivite Değerlendirme Anketi-Kısa Form'a göre 1 katılımcı düşük (2148 MET- dakika.hafta ${ }^{-1}$; Kategori 1), 8 katılımcl orta $\left(1847 \pm 837\right.$ MET- dakika.hafta-1 ${ }^{-1}$ Kategori 2), 16 katılımcı yüksek (5075 \pm 2437 MET- dakika.hafta-1 ${ }^{-1}$ Kategori 3) fiziksel aktivite düzeyine sahiptir (19). Katılımcllardan 24 saat öncesinde yüksek şiddette aktivite yapmamaları, bir gece öncesinde alkol, kahve, kafeinli içecek tüketmemeleri istenmiştir. Araştırma için Hacettepe Üniversitesi Girişimsel Olmayan Klinik Etik Kurulu'ndan izin alınmıştır (Karar No:2019/05-11).

İșlem Yolu: Katılımcılar son öğünlerinden en az 3 saat sonra laboratuvara davet edilmişlerdir. Boy ve vücut ağırlıkları ölçüldükten sonra telemetrik kalp atım monitörü bağlanmış ve en az 20 dakika oturur pozisyonda dinlendirilmişlerdir. Katılımcıların egzersiz öncesi ilk BIA ölçümünden en az 90 dakika önce muhtemel dehidrasyonu engellemek için $500 \mathrm{ml}$ su tüketmeleri sağlanmıştır. Daha sonra BIA A-A $_{\text {A }}$ ve BIA $\mathrm{B}_{\mathbf{E}-\mathrm{A}}$ teknolojileri kullanılarak VYY ve YVK ölçümleri yapılmıştır. Benzer yaş grubunda sağlıklı yetişkin erkeklerde ayaktan ayağa (Tanita) ve elden ayağa BIA teknolojisinin YVK için test-tekrar test sınıf içi güvenirlik katsayıları sırasıyla $r=$ 0.947 ve 0.950, BodPod (Air displacement plethysmography) yöntemi referans olarak kullanıldığında geçerlik katsayıları sırasıyla 0.934 ve 0.935 'dir (20). Elli $\mathrm{kHz}$ akım hücre içerisine tam olarak nüfuz edemediği için hücre içi sıvısını ölçmede yetersiz kaldığından, $(8,21)$ TVS ölçümü değerlendirilmemiştir. BIA uygulamasından sonra katılımcılara bisiklet ergometresinde tekrarlı sprint egzersizi yaptırılmıștır. Tekrarlı sprint testinde sirkadien ritmin zirve performans üzerine pozitif etkisi öğleden sonra gözlendiği için (22) tüm ölçümler 15.30-17.00 saatleri arasında yapılmıștır. Egzersizden hemen sonra (1-3 dakika), 10. ve 20. dakikalarda BIA $_{A-A}$ ve BIAE-A ölçümü yapılmıştır.

Boy ve Vücut Ağırlığı: Katılımcların boy uzunlukları duvara monte stadiyometrede (Holtain Ltd, UK) $\pm 0.1 \mathrm{~cm}$ hata ile bir kez ölçülmüştür. Vücut ağırlığı her BIA uygulamasında elektronik baskülde (Tanita TBF401A, USA) $\pm 0.1 \mathrm{~kg}$ hata ile kayıt edilmiştir.

Ayaktan Ayağa Bioelektrik İmpedans Analizi: $\mathrm{BIA}_{\mathrm{A}-\mathrm{A}} 50 \mathrm{kHz}$ tek frekans ve $500 \mu \mathrm{A}$ akım veren bir tetrapolar analizörde (Tanita TBF401A, USA) ölçülmüştür. BIA $\mathrm{A}_{\mathrm{A}-\mathrm{A}}$ ölçümü için katılımcının çıplak ayak ile analizörün tablasındaki elektrotların üzerine basarak hareketsiz durması istenmiştir. Üretici firmanın kullandığı kestirim formülünden vücut kompozisyonu parametreleri (VYY, YVK) ve impedans $(\Omega)$ değerleri cihazın yazıcısından otomatik çıktı şeklinde kayıt edilmiştir. Bu işlem egzersiz öncesinde ve egzersizden sonra 1., 10. ve 20. dakikalarda tekrarlanmıştır.

Elden Ayağa Biyoelektrik İmpedans Analizi: BIA $_{\text {E-A }}$ ölçümü suni deri kaplı bir masaj masası üzerinde yapılmıştır. Katılımcı masaya sırt üstü yattıktan sonra, kolları vücudundan yaklaşık $30^{\circ}$ ve bacakları yaklaşık $45^{\circ}$ açık bir şekilde pozisyonlandırılmıştır. BIA $\mathrm{E}_{\mathrm{E}-\mathrm{A}} 50 \mathrm{kHz}$ tek frekans ve $800 \mu \mathrm{A}$ akım veren ikisi toprak, ikisi kaynak (ölçüm) olmak üzere 4 elektrotlu $(\mathrm{Ag} / \mathrm{AgCl}$ Asumed, Türkiye) tetrapolar analizörde (Biodynamics Model 310e) ölçülmüştür. İki elektrot katılımcının sağ el ve bileği üzerine; biri elin dorsal yüzeyine 3 . metakarpofarengeal eklemin $1 \mathrm{~cm}$ proksimaline (toprak elektrotu), diğeri bileğin dorsal yüzeyine ulnanın başı hizasında 
bilek çizgisinin merkezine (ölçüm elektrotu) yapıştırılmıştır. İki elektrot ise katılımcının sağ ayak ve ayak bileği üzerine; biri ayağın dorsal yüzeyine 2. metatarsofalangeal eklemin $1 \mathrm{~cm}$ proksimaline (toprak elektrodu), diğeri bileğin dorsal yüzeyine lateral ve medial malleol arasını ortalayacak şekilde (ölçüm elektrotu) yapıştırılmıştır. Tüm elektrotlar aralarında en az $5 \mathrm{~cm}$ mesafe olacak şekilde katılımcının el ve ayak bölgelerine yerleştirilmiştir. Üretici firmanın kullandığı kestirim formülünden vücut kompozisyonu parametreleri (VYY, YVK) ile rezistans $(\Omega)$ ve reaktans (Xc) değerleri cihazın yazıcısından otomatik olarak çıktı şeklinde kayıt edilmiștir. Bu işlem egzersiz öncesinde ve egzersizden sonra 3., 10. ve 20. dakikalarda tekrarlanmıştır. BIA $A_{\mathrm{E}-\mathrm{A}}$ ölçüm öncesinde postural değişime bağlı olarak BIA değerlerinin stabilizasyonu için (23) katılımcılar 3 dakika yatırılmışlardır.

5 x 6 saniye Tekrarlı Sprint Testi (TST): Bilgisayar bağlantılı mekanik bisiklet ergometresinde (Monark, 894 E, Sweden) yapılmıştır. Katılımcı 90-120 W iş yükünde 5 dakika ısındırılmış ve sonrasında 3 dakika açma-germe egzersizlerinin ardından vücut ağırlığının \%10'una karşılık gelen dış dirence karşı 30 saniye pasif toparlanmalı $5 \times 6$ saniye tekrarlı sprint testine katılmıştır. Kalp atım hızı telemetrik KAH mönitörü (Polar, RS800, Finland) kullanılarak test boyunca 1 saniye zaman aralığ ile kayıt edilmiştir. Güç çıktısı değerleri bilgisayardaki yazılım programı tarafından hesaplanmıştır. Test sırasında ölçülen en yüksek kalp

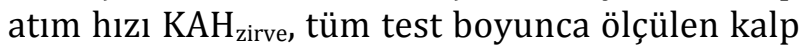
atım hızının ortalaması $\mathrm{KAH}_{\text {ort }}$ olarak dikkate alınmıștır. Test sonunda algılanan zorluk derecesi 15 dereceli (6-20 ölçekli) Borg skalası ile belirlenmiştir (24). Katılımcılar test boyunca sözel olarak motive edilmişlerdir.

Verilerin Analizi: Yüksek şiddetli egzersizin vücut kompozisyonu (VYY ve YVK) ve biyoelektrik impedans parametreleri (impedans, rezistans ve reaktans) üzerine etkisini değerlendirmek için gerekli örneklem boyutu G*Power programinda (ver 3.1.9.2) $\alpha=0.05$, Power $=$ $0.90(1-\beta)$ ve tek örneklem 4 gözlem Tekrarlı Ölçümlerde Denekiçi Faktör dizaynı için $n=22$ hesaplanmıştır (25). Tanımlayıcı istatistik yöntemleri ile ortalama ve standart sapma hesaplandıktan sonra, verilerin normal dağılıma uyumları Kolmogorof-Smirnov Testi ile belirlenmiştir. Verilerin küresellik varsayımına uyumu Mauchly's Testi ile kontrol edilmiștir. Küresellik varsayımı yerine gelmeyen değişkenlerde serbestlik derecesi için Epsilon $(\varepsilon)<0.75$ ise Greenhouse-Geisser, $\varepsilon>0.75$ ise Huynh-Feldt düzeltmesi uygulanmıştır (26). Yüksek şiddette egzersizin vücut komposizyonu parametreleri üzerine etkisi Tekrarlı Ölçümlerde Varyans Analizi ile Test edilmiştir. F istatistiği anlamlı çıktığında fark Bonferroni Post Hoc Test ile belirlenmiştir. Deneme etkisinin boyutu için kısmi eta kare $\left(\eta_{2}\right)$ hesaplanmıştır. Kısmi $\eta_{2} ; 0.01=$ küçük, $0.06=$ orta ve $0.14=$ büyük etki olarak sınıflandırılmıştır (27). VYY'de egzersiz öncesi ile sonrasında, 10 . ve 20 . dakikalarda meydana gelen bireysel seviyedeki değişimler BlandAltman grafikleme ile değerlendirilmiştir (28). Tüm istatistiksel işlemler SPSS paket programında (Versiyon 22.0) yapılmış ve 0.05 yanılma düzeyi kullanılmıştır.

\section{BULGULAR}

Katılımcıların TST'de ölçülen KAH ve algılanan zorluk derecesi ve güç çıktıları Tablo 1'de gösterilmiştir. Ölçülen güç parametreleri, fizyolojik cevaplar ve algılanan zorluk derecesi testin yüksek şiddette olduğunun göstergesi olarak kabul edilebilir (Tablo 1). Test öncesi VA=79.62 \pm 9.51 $\mathrm{kg}$, test sonrası 1., 10 . ve 20 dakikalarda sirasiyla $79.55 \pm 9.48,79.48 \pm 9.48$ ve $79.42 \pm 9.49$ kg ölçülmüştür. Yüksek şiddette egzersizin VA üzerine etkisi anlaml bulunmuştur $\left(\mathrm{F}_{(1.56 ; 37.80)}=22.55 ; \mathrm{p}<0.001, \eta_{2}=0.484\right)$. Dinlenik ve egzersizden hemen sonrasina göre 10 . dakikadan itibaren VA'da anlamlı derecede azalma gözlenmiş olmakla beraber $(\mathrm{p}<0.05)$, egzersiz öncesine göre bu azalma $\leq \% 0.25^{\prime}$ dir.

Yüksek şiddette kesintili egzersiz öncesi ve sonrasında BIAA-A yöntemi ile ölçülen impedans ve vücut kompozisyonu parametrelerindeki değişimler ve ANOVA istatistiğine ait bulgular Tablo 2 'de gösterilmiştir. Yüksek şiddette egzersizin $\mathrm{BIA}_{\mathrm{A}-\mathrm{A}}$ impedans değerleri üzerine akut etkisi anlamlı bulunmuştur $\left(\mathrm{F}_{(2.16 ; 51.88)}=10.53 ; \mathrm{p}<0.001\right.$, 
$\eta_{2}=0.305$ ). Egzersiz öncesi ile karşılaștırıldığında, egzersizden hemen sonra ölçülen impedans anlamlı derecede düşüktür ve 20. dakikaya kadar düşük kalmıştır. Egzersizin $\mathrm{BIA}_{\mathrm{A}-\mathrm{A}}$ yöntemi ile belirlenen VYY $\left(\mathrm{F}_{(3 ; 72)}=12.03\right.$; $\left.\mathrm{p}<0.001, \eta_{2}=0.334\right)$ ve $\mathrm{YVK}\left(\mathrm{F}_{(2.16 ; 51.91)}=4.97\right.$; $\mathrm{p}<0.01, \eta_{2}=0.172$ ) üzerine etkisi de anlamlıdır. Egzersizden hemen sonra, 10. ve 20. dakikalarda ölçülen VYY değerleri egzersiz öncesinden anlamlı derecede düşüktür $(\mathrm{p}<0.01)$. Buna karşılık YVK egzersizden hemen sonra anlamlı derecede artmış $(\mathrm{p}<0.001)$ ancak 10. dakikadan itibaren egzersiz öncesi değere benzer bulunmuştur ( $>0.05)$. Egzersiz öncesi ile karşılaştırıldığında egzersiz sonrasinda VYY'de düşüş \%2.0'den, YVK artış ise \%0.40'dan azdır.
Tablo 1. Katılımcların tekrarlı sprint testinde ölçülen KAH, AZD ve güç çıktıları.

\begin{tabular}{llll}
\hline & Min & Maks & X \pm SD \\
\hline ZG (W.kg-1) & 9.8 & 14.3 & $11.5 \pm 1.2$ \\
OG (W.kg-1) & 8.5 & 12.8 & $10.2 \pm 1.1$ \\
PDY (\%) & 5.0 & 23.0 & $11.5 \pm 5.4$ \\
KAHDin (a.dk-1) & 58.0 & 112.0 & $72.7 \pm 11.7$ \\
KAHzirve (a.dk ${ }^{-1}$ ) & 156.0 & 201.0 & $177.1 \pm 10.4$ \\
KAHort (a.dk ${ }^{-1}$ ) & 124.0 & 178.0 & $155.0 \pm 14.6$ \\
AZD & 12.0 & 19.0 & $16.6 \pm 1.8$ \\
\hline
\end{tabular}

KAH:Kalp atım hizl, AZD:Algilanan zorluk derecesi, ZG:Zirve güç, OG:Ortalama güç, PDY:Performans düşüş yüzdesi.

Tablo 2. Yüksek şiddette kesintili egzersizden önce (dinlenik) ve sonra ayaktan ayağa BIA yönteminde impedans ve vücut kompozisyonu bileșenleri.

\begin{tabular}{|c|c|c|c|c|c|c|}
\hline & E_Ö & ES_1 & ES_10 & ES_20 & $\mathbf{p}$ & $\eta_{2}$ \\
\hline IMPEDANS $_{\mathrm{A}-\mathrm{A}}(\Omega)$ & $466.7 \pm 52.4$ & $459.0 \pm 50.2$ & $460.2 \pm 50.9$ & $460.4 \pm 53.0$ & 0.001 & 0.305 \\
\hline VYY BIA $A-A(\%)$ & $20.71 \pm 4.56$ & $20.33 \pm 4.54$ & $20.36 \pm 4.44$ & $20.29 \pm 4.50$ & 0.001 & 0.334 \\
\hline YVK $\left(B I A_{A-A}\right)(\mathrm{kg})$ & $62.76 \pm 4.41$ & $63.01 \pm 4.34$ & $62.93 \pm 4.44$ & $62.94 \pm 4.50$ & 0.001 & 0.179 \\
\hline
\end{tabular}

E_Ö: Egzersiz öncesi, ES_1: Egzersiz sonrası 1. dakika, ES_10: Egzersiz sonrası 10. dakika, ES_20: Egzersiz sonrası 20. dakika,

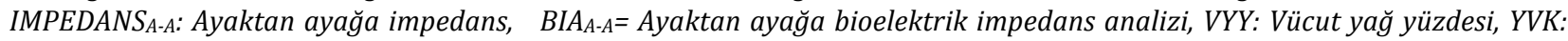
yağsız vücut kitlesi

Tablo 3. Yüksek şiddette kesintili egzersizden önce (dinlenik) ve sonra elden ayağa BIA yönteminde rezistans, reaktans ve vücut kompozisyonu bileşenleri.

\begin{tabular}{lllllll}
\hline & E_0̈ & ES_3 & ES_10 & ES_20 & p & $\boldsymbol{\eta}_{2}$ \\
\hline REZISTANS $_{\text {E-A }}(\boldsymbol{\Omega})$ & $486.3 \pm 57.6$ & $478.0 \pm 64.2$ & $478.6 \pm 60.9$ & $474.6 \pm 58.6$ & 0.020 & 0.145 \\
REAKTANS $_{\text {E-A }}(\boldsymbol{\Omega})$ & $64.0 \pm 10.2$ & $61.2 \pm 9.0$ & $60.8 \pm 9.5$ & $61.1 \pm 8.8$ & 0.101 & 0.108 \\
VYY BIA $_{\text {E-A }}(\%)$ & $18.93 \pm 4.70$ & $18.32 \pm 4.75$ & $18.36 \pm 5.02$ & $18.12 \pm 4.86$ & 0.057 & 0.110 \\
YVK (BIAE-A) $(\mathbf{k g})$ & $64.68 \pm 9.75$ & $65.13 \pm 9.87$ & $65.01 \pm 9.83$ & $65.18 \pm 9.95$ & 0.140 & 0.078 \\
\hline
\end{tabular}

E_Ö: Egzersiz öncesi, ES_3: Egzersiz sonrası 3. dakika, ES_10: Egzersiz sonrası 10. dakika, ES_20: Egzersiz sonrası 20. dakika,

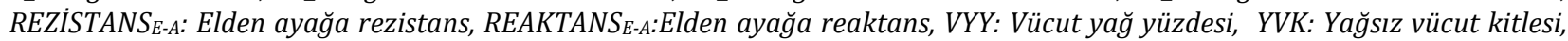
$B I A_{E-A}$ Elden ayağa biyoelektrik impedans analizi.

Yüksek şiddette kesintili egzersiz öncesi ve sonrasında BIA $A_{E-A}$ yöntemi ile ölçülen rezistans, reaktans ve vücut kompozisyonu parametrelerindeki değişimler ve ANOVA istatistiğine ait bulgular Tablo 3'de gösterilmiştir. Yüksek şiddette egzersizin rezistans $\left(\mathrm{F}_{(2.21 ; 50,03)}=4.06 ; \mathrm{p}=0.020\right.$, $\eta_{2}=0.145$ ) üzerine akut etkisi anlamlı bulunmuştur. Egzersiz öncesi ile karşılaştırıldığında egzersizden hemen sonra ve 10 . dakikada ölçülen rezistans değerleri değişmemiş ancak 20 
dakika sonra anlamlı derecede düşmüştür $(\mathrm{p}<0.001)$. Yüksek şiddette egzersizden 20 dakika sonra rezistansta meydana gelen düşüş \%2.4'den azdır. Buna karşılık, yüksek şiddette egzersiz $\mathrm{BIA}_{\mathrm{E}-\mathrm{A}}$ yönteminde ölçülen reaktans $\left(\mathrm{F}_{(1.18 ; 27.25)}=2.79 ; \mathrm{p}=0.101, \eta_{2}=0.108\right)$ değerlerinde anlamlı bir değișime neden olmamıștır. Yüksek şiddette kesintili egzersizin BIA $A_{E-A}$ yöntemi ile belirlenen VYY üzerine etkisi de anlaml bulunmuştur $\left(\mathrm{F}_{(3 ; 72)}=3.00 ; \mathrm{p}=0.036\right)$ ancak küresellik varsayımı yerine gelmediği için (KiKare $=27.34 ; \mathrm{p}<0.001 ; \varepsilon=0.693$ ) serbestlik derecelerine Greenhouse-Geisser düzeltmesi uygulandığında yüksek şiddette kesintili egzersizin VYY üzerine etkisi anlamsız bulunmuştur $\left(\mathrm{F}_{(2.08 ; 49.93)}=3.00 ; \mathrm{p}=0.057\right)$. Bununla beraber BIAE-A yönteminde egzersiz öncesine göre egzersiz sonrasında VYY'de değişim $\leq \% 4.3$ 'dür. Benzer şekilde egzersiz sonrası ölçülen YVK egzersiz öncesinden yüksek olmakla beraber anlamlı değildir $\quad\left(\mathrm{F}_{(2.06 ; 49.80)}=2.03 ; \quad \mathrm{p}=0.140\right.$, $\eta_{2}=0.078$ ).

Her iki yöntemle egzersizden hemen sonra, 10. ve 20. dakikalarda belirlenen VYY değerlerinin egzersiz öncesinde ölçülen değerlerle tutarlık sinırları, fark ortalamaları ve farkların ortalama VYY((EÖ_VYY+ES_VYY)/2) değerleriyle olan ilişkisi (trend) Şekil 1'de gösterilmiştir. BIA $A_{A-A}$ yönteminde egzersiz öncesi ile sonrasında belirlenen VYY değerleri arasındaki fark (hata) ortalamaları; egzersizden hemen sonrası için \%$0.38,10$. dakika için $\%-0.35$ ve 20 . dakika için $\%-0.42$, BIA $\mathrm{E}_{\mathrm{A}}$ yönteminde ise; egzersizden hemen sonrası için \%-0.62, 10. dakika için \%-0.57 ve 20. dakika için \%-0.81 hesaplanmıștır. Bu değerler her iki yöntemde de egzersiz öncesine göre egzersiz sonrasında belirlenen VYY değerlerinin daha düşük olduğunu göstermektedir. Ek olarak her iki yöntemde egzersiz öncesinde ve egzersiz sonrasinda tüm zamanlarda belirlenen VYY farkları ile ortalama VYY arasında anlamlı ilişskiler saptanmamıștır (Şekil 1). Bir başka de- yişle, egzersiz öncesinde belirlenen VYY ile egzersiz sonrasında tüm zamanlarda belirlenen VYY arasındaki farklar sabittir (homoscedastic). $\mathrm{Bu}$ bulgular egzersiz öncesinde belirlenen VYY ile egzersiz sonrasında tüm zamanlarda belirlenen VYY arasındaki farkların (egzersiz etkisinin) ölçülen VYY değerlerinin boyutundan bağımsız olduğunu göstermektedir.

\section{TARTIŞMA}

$\mathrm{Bu}$ çalışmanın amacı, kısa süreli yüksek şiddetli egzersizin (5x6 sn tekrarlı sprint) elden ayağa ve ayaktan ayağa BIA'dan belirlenen vücut kompozisyonu üzerine akut etkisini incelemektir. Bu çalışmanın ana bulguları yüksek şiddette kısa süreli egzersizin BIA $_{A-A}$ yöntemi ile belirlenen vücut kompozisyonunda anlamlı değişime neden olmakla beraber bu değişimin çok düşük düzeyde (\%2'den az) olduğunu (Tablo 2), BIA $A_{E-A}$ yöntemi ile belirlenen vücut kompozisyonunda ise önemli bir değişime neden olmadığını göstermiştir (Tablo 3).

Biyolojik dokuların elektriği iletme özellikleri intra ve ekstrasellüler alan sıvısının dağılımına ve hücre zarlarının biyokimyasal yapısına göre değişkenlik göstermektedir (7). Vücut bölümleri arasında sıvı dağılımı postüre (29) ve egzersize (aerobik) (30) bağlı olarak değişkenlik gösterir. Egzersizde plazma $\left[\mathrm{K}^{+}\right]^{\prime}$ da artış, $\left[\mathrm{Na}^{+}\right]$ve $\left[\mathrm{Cl}^{+}\right]$ iyonlarında değişim gözlenmemesi (30), egzersizin vücut bölümleri arasında sıvı değişimi ve elektrolit dengesinde bozulmaya neden olabileceğinin delili olarak kabul edilebilir. İzokinetik bisiklette yaplan 30 saniye sprint egzersizinden sonra 10. dakikaya kadar plazma hacminin azaldığı ve elektrolit içeriğinin değiştiği, egzersiz öncesine göre $\left[\mathrm{K}^{+}\right]$ve $\left[\mathrm{Na}^{+}\right]$iyonlarının plazmadan aktif kaslara doğru kaydığı gözlenmiștir (14). Bu bulgular hem aerobik hem de anaerobik egzersizlerin vücut bölümleri arasında sıvı ve elektrolit dağılımını önemli ölçüde değiştirdiğini göstermektedir. 

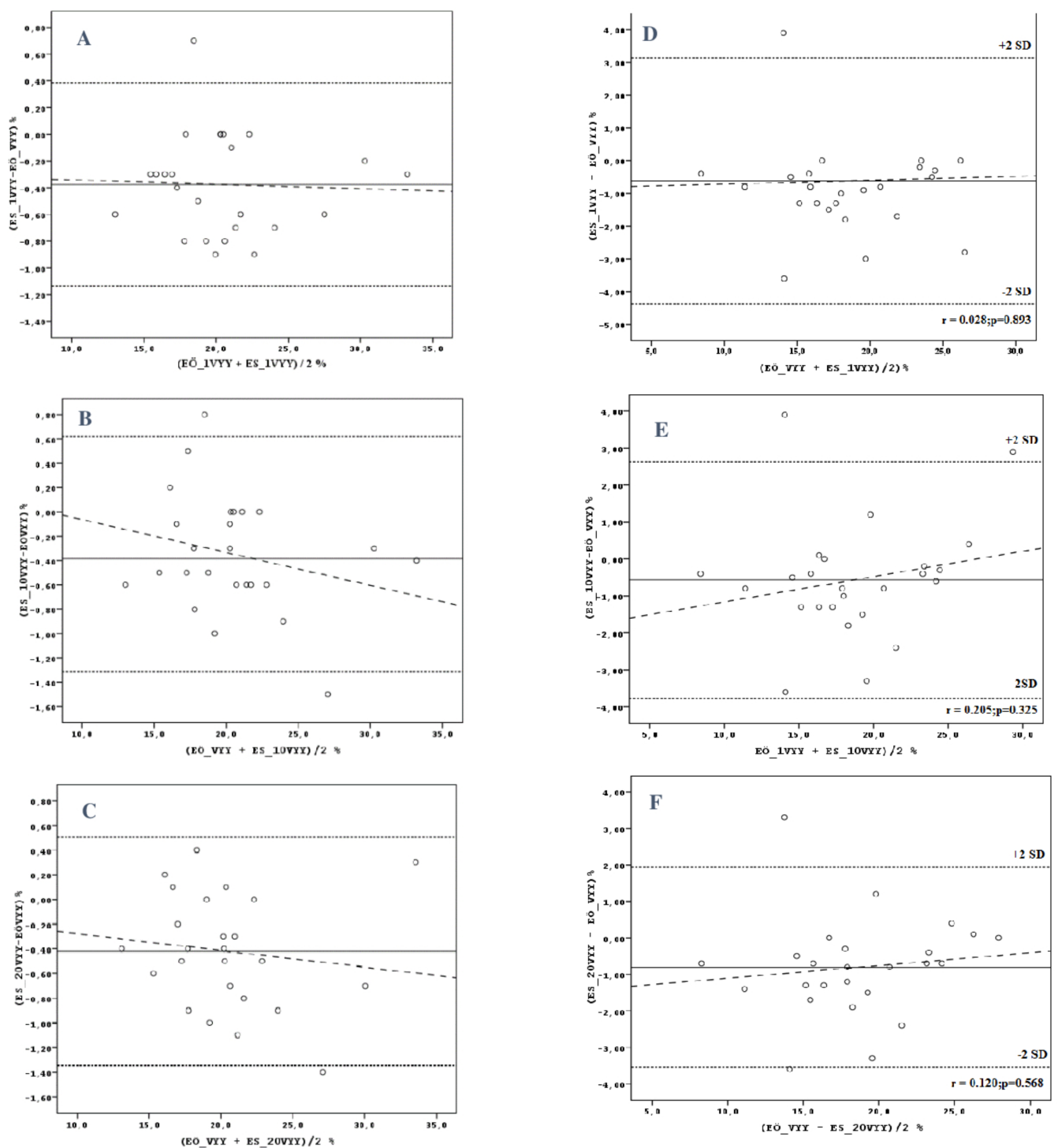

Şekil 1. Egzersiz öncesinde ve sonrasında BIAA_A (A:Egzersizden hemen sonra, B:10. Dakika sonra, C:20. dakika sonra) ve BIAE-A (D: Egzersizden hemen sonra, E:10. dakika sonra, F:20. dakika sonra) yöntemleri ile belirlenen VYY için Bland-Altman grafikleme ile gösterilen tutarlık sınırları. Sürekli çizgi: Hata (fark) ortalaması, Kesintili çizgiler: Alt ve üst tutarlık sınırları, Noktalı çizgi: Hata (fark) değerleri ve VYY ortalama ((Eti VYY + ES VYY) /2) değerleri arasındaki ilişki çizgisi.

Yukarıdaki çalıșmaların bulguları, egzersizin akut etkisinin vücut kompozisyonunun hesaplanmasinda kullanılan BIA teknolojisi çıktılarından impedans, rezistans ve reaktans değerlerini değiştirme potansiyeline sahip olduğunun bir göstergesi olarak kabul edilebilir (31).
Aerobik egzersizlerin ve kuvvet antrenmanlarının etkilerinin incelendiği diğer çalıșmalarda olduğu gibi, bu çalışmada da kısa süreli yüksek şiddetli egzersiz sonrasında her iki BIA yöntemiyle ölçülen impedans ve rezistans değerlerinde anlamlı düşüş gözlenmiştir (Tablo 2 ve 3 ). 
Yirmi dakika süreli (6x10 tekrar) skuat egzersizlerinden hemen sonra plazma hacminde \%22 azalma, aktif kasların kas kesit alanında \%5-10 oranında hacimsel artış rapor edilmiştir (16). Bu bulgular alt ekstremite kaslarına yönelik şiddetli egzersizlerin vasküler alandan aktif dokulara önemli miktarda sıvı kayması nedeniyle dokularda elektrik akımına karşı ortaya çıkan dirençlerin azalmasının nedeni olarak kabul edilebilir. Bundan dolayı bireyin ölçüm öncesindeki fiziksel aktivite durumu, BIA ile belirlenen vücut kompozisyonunu önemli ölçüde değiştirebileceği için, genel olarak BIA test yönergelerinde ve uygulamalarında en az 12-48 saat önce şiddetli egzersizin sonlandırılması tavsiye edilmektedir (32-34). Her ne kadar egzersiz plazma ve aktif kaslarda sıvı ve elektrolit dengesinde ve impedans/rezistans değerlerinde önemli değişime neden oluyorsa da bu durumun yetişkin ve çocuklarda BIA'dan belirlenen vücut kompozisyonu üzerine etkisi tartışmalıdır. Bazı çalışmalarda yetişkin ve çocuklarda aerobik egzersizin şiddeti arttıkça egzersiz sonrası vücut kompozisyonun önemli ölçüde değiștiği $(10,11,35)$, diğer çalışmalarda egzersizin şiddetinden bağımsız olarak vücut kompozisyonunun etkilenmediği rapor edilmiştir $(36,37)$. Örneğin, maksimum kalp atım hızının \%70 ve 85 'inde yapılan 30 dakika bisiklet egzersizi sonrasında BIA $\mathrm{A}_{\mathrm{A}-\mathrm{A}}$ ile elde edilen vücut yağ yüzdesinde (VYY) önemli azalma saptanmıştır (10). Bununla beraber maksimal oksijen tüketimi testi yapılan 7-10 yaş erkek ve kız çocuklarda test öncesi ve sonrası BIA A-A yöntemi ile ölçülen vücut kompozisyonu parametrelerinde (yağ ağırlık, yağsız vücut kitlesi (YVK), total vücut suyu (TVS), vücut ağırlığı (VA)) anlamlı fark saptanmamıştır (36).

Yetişkinlerde uzun süreli aerobik egzersizlerin ve kuvvet antrenmanlarının etkisinin incelendiği önceki çalışmaların ve kısa süreli, yüksek şiddetli egzersizin etkisinin incelendiği bu çalışmanın bulguları BIA öncesinde 12-48 saat süreyle egzersize ara verilmesi gereğini desteklememektedir. Örneğin, yakın zamanda sınırlı sayıda erkekte $(n=9)$ yapılan bir çalışmada, orta ve yüksek şiddetli 30 dakika koşu bandı egzersizinden hemen ve 60 dakika sonra elden ayağa BIA ile belirlenen VYY ve YVK'da anlamlı bir de- ğişim gözlenmemiștir (9). Benzer şekilde geniș bir denek grubunda (45 erkek, 41 kadın) bir tekrar maksimal kuvvetin \%65-75'inde 3x10-12 tekrarlı 8 farklı egzersiz içeren 60 dakika süren kuvvet egzersizinden 60 dakika sonra ayaktan ayağa BIA'da ölçülen impedans ve vücut kompozisyonu parametrelerinde (VYY, YVK) anlamlı bir değişim gözlenmemiştir (17). Bu çalışmada, önceki çalışmalarda olduğu gibi kısa süreli yüksek şiddetli egzersiz sonrasında elden ayağa BIA teknolojisi kullanılarak belirlenen VYY ve YVK'de anlamlı değișim saptanmamıștır (Tablo 3). Buna karşılık, ayaktan ayağa BIA teknolojisinde VYY'de anlamlı azalma, YVK'da anlamlı artış saptanmıștır, ancak bu değișimler $\% 2.0$ ve \%0.40 dan az olduğu için pratik olarak kabul edilebilir düzeydedir (Tablo 2). Bland-Altman grafikleme yönteminde de egzersizden hemen sonra, 10. ve 20. dakikalarda ölçülen VYY değerlerinin egzersiz öncesine göre fark ortalamaları da oldukça düşüktür (sırasıyla -0.38 \pm 0.38, $0.35 \pm 0.48$ ve $-0.42 \pm 0.46$ ). Bunun yanında, egzersiz sonrası tüm zamanlarda belirlenen VYY değerlerine ait farkların \pm 2 SD tutarlılık alt ve üst sınırları içerisinde olması ve ölçüm değerlerinin boyutları ile anlamlı ilişki vermemesi egzersiz sonrasındaki değişimlerin bireysel seviyede sabit kaldığını, katılımcının VYY değerine bağlı olmadığını göstermektedir (Şekil 1). Bu çalışmada yüksek şiddetli kısa süreli egzersizlerin vücut kompozisyonu ve impedans çıtıları üzerine etkileri, düşük şiddet, uzun süreli aerobik egzersizlerin ve uzun süreli (60 dakika) kuvvet antrenmanlarının vücut kompozisyonu ve impedans çıktılarına olan etkilerine benzerdir. $\mathrm{Bu}$ çalışmanın bulguları da önceki çalışmalarda olduğu gibi BIA teknolojisi ile vücut kompozisyonun belirlenmesinden önce şiddetli fiziksel aktivite kısıtlamasının kanıta dayalı olmadığını $(9,11)$ desteklemektedir.

\section{SONUÇ}

Bu çalışmada kısa süreli yüksek şiddetli egzersizin hem BIA $A_{E-A}$ hem de BIA $A_{A-A}$ yöntemi ile belirlenen vücut kompozisyonu bileşenleri üzerinde önemli bir etkisi saptanmamıştır. BIA $A_{A-A}{ }^{\prime} d a$ VYY'nin egzersiz öncesine göre $\% 2.0^{\prime}$ den az düşmesi nedeniyle pratik olarak dikkate alınmayacak bir değişimi temsil ettiği söylenebi- 
lir. $\mathrm{Bu}$ çalışmanın bulguları ve önceki bazı çalışmaların bulguları BIA testlerinden önce 1248 saat süre ile egzersizlere ara verilmesinin kanıta dayalı olmadığını göstermektedir. Bu katı tavsiye VYY ve YVK'nın değerlendirilmesinde BIA teknolojilerinin pratik kullanım değerini düşürmektedir. Bunun yanında, gereksiz yere egzersiz programlarına ve özellikle yarıșma dönemi gibi performans için kritik öneme sahip antrenman periyodundaki uygulamalara ara verilmesine de neden olmaktadır. Bu nedenle, BIA teknolojileri kullanılarak vücut kompozisyonunun belirlenmesi için teste girecek kişinin 60-90 dakika önce sıvı tüketmesi sağlanarak, ya da idrar dansitesi ölçülerek hidrasyon durumunun kontrol edilmesi ve 20 dakika oturur pozisyonda dinlendirilmesi BIA yönteminin pratik kullanım değerini artıracaktır.

\section{KAYNAKLAR}

1. Houska CL, Kemp JD, Niles JS, et al. Comparison of body composition measurements in lean female athletes. Int J Exerc Sci. 2018;11(4):417-24.

2. Day K, Kwok A, Evans A, et al. Comparison of a bioelectrical impedance device against the reference method dual energy x-ray absorptiometry and anthropometry for the evaluation of body composition in adults. Nutrients. 2018;10(10):1469

3. Lozano Berges G, Matute Llorente Á, Gómez Bruton A, et al. Body fat percentage comparisons between four methods in young football players: are they comparable? Nutr Hosp. 2017;34(5):1119-24.

4. Ostojic SM. Estimation of body fat in athletes: skinfolds vs bioelectrical impedance. J Sports Med Phys Fitness. 2006;46(3):442-6.

5. Gagnon C, Ménard J, Bourbonnais A, et al. Comparison of foot-to-foot and hand-to-foot bioelectrical impedance methods in a population with a wide range of body mass indices. Metab Syndr Relat Disord. 2010;8(5):437-41.

6. Dittmar M. Comparison of bipolar and tetrapolar impedance techniques for assessing fat mass. Am J Hum Biol. 2004;16(5):593-7.

7. Lukaski HC, Johnson PE, Bolonchuk WW, et al. Assessment of fat-free mass using bioelectrical impedance measurements of the human body. Am J Clin Nutr. 1985; 41: 810-17.

8. Moon JR. Body composition in athletes and sports nutrition: An examination of the bioimpedance analysis technique. Eur J Clin Nutr. 2013;67: S54-S59.

9. Nickerson BS, Esco MR, Kliszczewicz BM, et al. Comparison of bioimpedance and underwater weighing body fat percentage before and acutely after exercise at varying intensities. $J$ Strength Cond Res 2017;31(5):1395-02.
10. Andreacci J, Nagle L, Fitzgerald T, et al. Effect of exercise intensity on percent body fat determined by legto-leg and segmental bioelectrical impedance analyses in adults. Res Q Exerc Sport. 2013;84(1): 88-95.

11. Dixon CB, Andreacci JL, Ledezma C. Effect of aerobic exercise on percent body fat using leg-to-leg and segmental bioelectrical impedance analysis in adults. Int $J$ Body Compos Res. 2008; 6(1):27-34

12. Demura S, Yamaji S, Goshi F, et al. The influence of transient change of total body water on relative body fats based on three bioelectrical impedance analyses methods. Comparison between before and after exercise with sweat loss, and after drinking. J Sports Med Phys Fitness. 2002;42: 38-44.

13. Lindinger MI, Heigenhauser GJ, McKelvie RS, et al. Blood ion regulation during repeated maximal exercise and recovery in humans. Am $J$ Physiol. 1992;262(1):126-36.

14. McKenna MJ, Heigenhauser GJ, McKelvie RS, et al. Sprint training enhances ionic regulation during intense exercise in men. J Physiol. 1997;501(3):687-702.

15. Boone CH, Hoffman JR, Gonzalez AM, et al. Changes in Plasma Aldosterone and Electrolytes Following HighVolume and High-Intensity Resistance Exercise Protocols in Trained Men. J Strength Cond Res. 2016;30(7):1917-23.

16. Ploutz-Synder LL, Convertino VA, Dudley GA. Resistance exercise-induced fluid shifts: change in active muscle size and plasma volume. Am J Physiol. 1995;269: 536-43.

17. Dixon CB, Andreacci JL. Effect of resistance exercise on percent body fat using leg-to-leg and segmental bioelectrical impedance analysis in adults. J Strength Cond Res. 2009;23(7): 2025-32.

18. Body Mass Index, WHO, Erişim tarihi 20 Mayıs 2019, www.euro.who.int/en/health-topics/diseaseprevention/nutrition/a-healthy-lifestyle/ body-massindex-bmi

19. Cheng HL. A simple easy-to-use spreadsheet for automatic scoring of the International Physical Activity Questionnaire (IPAQ) Short Form (updated November 2016). 2016.

20. Vasold KL, Parks AC, Phelan DML, et al. Reliability and validity of commercially available low-cost bioelectrical impedance analysis. Int J Sport Nutr Exerc Metab. 2019;29(4):406-10.

21. Jaffrin MY, Morel H. Body fluid volumes measurements by impedance: A review of bioimpedance spectroscopy (BIS) and bioimpedance analysis (BIA) methods. Med Eng Phys. 2008;30(10): 1257-69.

22. Zarrouk N, Chtourou H, Rebai H, et al. Time of day effects on repeated sprint ability. Int J Sports Med. 2012;33(12):975-80.

23. Küçükkubaş N, Hazır T, Açıkada C. 15-17 yaş ergen erkeklerde biyoelektrik impedans yönteminde ölçüm aralığının belirlenmesi. Spor Bilimleri Dergisi. 2006;17(2):38-47.

24. Borg GA. Psychophysical bases of perceived exertion. Med Sci Sports Exerc. 1982;14(5):377-81. 
25. Faul F, Erdfelder E, Lang AG et al. G*Power 3: A flexible statistical power analysis program for the social, behavioral, and biomedical sciences. Behav Res Methods. 2007;39: 175-91.

26. Winter EM, Eston RG, Lamb KL. Statistical analyses in the physiology of exercise and kinanthropometry. $J$ Sports Sci. 2001;19(10):761-75.

27. Richardson JT. Eta squared and partial eta squared as measures of effect size in educational research. Educ Res Rev. 2011;6(2):135-47.

28. Bland JM, Altman DG. Statistical methods for assessing agreement between two methods of clinical measurement. Lancet. 1986;8476:307-10.

29. Maw GJ, Mackenzie IL, Taylor NAS. Redistribution of body fluids during postural manipulations. Acta Physiol Scand. 1995;155(2):157-63.

30. Pivarnik JM, Goetting MP, Senay LC. The effects of body position and exercise on plasma volume dynamics. Eur J Appl Physiol Occup Physiol. 1986;55(4):450-6.

31. Deurenberg P, Weststrate J, Paymans I, et al. Factors affecting bioelectrical impedance measurements in humans. Eur J Clin Nutr. 1988;42:1017-22.
32. Lee LW, Liao YS, Lu HK, et al. Validation of two portable bioelectrical impedance analyses for the assessment of body composition in school age children. PLOS One. 2017;12(2): $\mathrm{e} 0171568$.

33. Chen KT, Chen YY, Wang CW, et al. Comparison of standing posture bioelectrical impedance analysis with DXA for body composition in a large, healthy Chinese population. PloS One. 2016;11(7):e0160105

34. Heyward VH, Wagner DR. Applied Body Composition Assessment. 2nd ed. Champaign IL: Human Kinetics; 2004.

35. Romanowski KL, Fradkin AJ, Dixon CB, et al. Effect of an acute exercise session on body composition using multi-frequency bioelectrical impedance analysis in adults. Journal of Sports Science 2015;3:171-78.

36. Andreacci JL, Dixon CB, Lagomarsine M, et al. Effect of a maximal treadmill test on percent body fat using legto-leg bioelectrical impedance analysis in children. $J$ Sports Med Phys Fitness. 2006;46(3):454-7.

37. Goss FL, Robertson RJ, Dube J, et al. Does exercise testing affect the bioelectrical impedance assessment of body composition in children? Pediatr Exerc Sci. 2003;15(2): 216-22. 